\title{
Infant and Early Childhood Exposure to Adult-Directed and Child-Directed Television Programming \\ Relations with Cognitive Skills at Age Four
}

\author{
Rachel Barr, Alexis Lauricella, Elizabeth Zack, and Sandra L. Calvert \\ Georgetown University
}

\begin{abstract}
This study described the relations among the amount of child-directed versus adult-directed television exposure at ages 1 and 4 with cognitive outcomes at age 4 . Sixty parents completed 24-hour television diaries when their children were 1 and 4 years of age. At age 4, their children also completed a series of cognitive measures and parents completed an assessment of their children's executive functioning skills. High levels of exposure to programs designed for adults during both infancy and at age 4, and high levels of household television use at age 4, were all associated with poorer executive functioning at age 4 . High exposure to television programs designed for adults during the preschool years was also associated with poorer cognitive outcomes at age 4 . In contrast, exposure to television programs designed for young children at either time point was not associated with any outcome measure at age 4 . These results suggest that exposure to child-directed versus adult-directed television content is an important factor in understanding the relation between media exposure and developmental outcomes.
\end{abstract}

Rachel Barr, Alexis Lauricella, Elizabeth Zack, and Sandra L. Calvert, Department of Psychology.

This research was supported by a gift from the Stuart Family Foundation to the Children's Digital Media Center at Georgetown University, and we thank them for their financial support. We also thank the children and parents who made this research possible, as well as Beverly Good and Kimberly Nguyen for assisting with data collection, and Rusan Chen for assisting with the statistical analysis.

Address correspondence to Rachel Barr, 306 White-Gravenor Hall, Department of Psychology, Georgetown University, Washington, DC 20057-1001. Phone (202) 687-4042. E-mail: rfb5@georgetown.edu.

Merrill-Palmer Quarterly, January 2010, Vol. 56, No. 1, pp. 21-48. Copyright (C 2010 by Wayne State University Press, Detroit, MI 48201. 
Merrill-Palmer Quarterly

In 1997, the Baby Einstein series marked the entry of the first baby videos into the marketplace (Garrison \& Christakis, 2005). A decade later, only a handful of studies have examined associations between early television exposure and later developmental outcomes. A few studies support the American Academy of Pediatrics (1999) recommendation that children under the age of 2 should not be exposed to television programs, reporting deleterious effects of early television exposure on later attention and cognitive skills (Christakis, Zimmerman, DiGiuseppe, \& McCarty, 2004; Lanhuis, Poulton, Welch, \& Hoancox, 2007; Zimmerman \& Christakis, 2005, 2007). However, other researchers found no association between early television exposure on later developmental outcomes (Gentzkow \& Shapiro, 2008; Mistry, Minkovitz, Strobino, \& Borzekowski, 2007; Obel et al., 2004; Stevens \& Mulsow, 2006). These longitudinal studies focused primarily on the associations between early television exposure and cognitive measures, including executive functioning and school readiness.

The purpose of the present research is to describe the associations between early exposure to television programs designed for adults versus early exposure to television programs designed specifically for very young children. We discuss the negative outcomes associated with television viewing, the role that content may play in arriving at those findings, and our hypotheses regarding the associations between early and concurrent exposure to different types of television content and later cognitive skills.

\section{Cognitive Skills and the Amount of Television Exposure}

Executive functioning. Executive functioning is the product of a complex cognitive regulatory system that helps guide behavior in a goal-directed manner (Hughes, 2002). Executive functioning encompasses a range of processes, including (1) inhibition (the ability to refrain from performing an action), (2) working memory (the ability to hold information in mind in order to complete a task), (3) the ability to shift attention between two competing tasks, and (4) emotion regulation (the ability to monitor and respond to changes in emotional state). Executive functioning is critical for school readiness because schools require children to control impulses, follow directions, transition smoothly between activities, and focus attention on relevant task information. Research has shown that executive functioning skills develop rapidly during the first 5 years of life (Espy, 1997; Gerstadt, Hong, \& Diamond, 1994; Isquith, Gioia, \& Espy, 2004; Zelazo, Carter, Reznick, \& Frye, 1997).

Some research suggests that heavy exposure to television programming disrupts executive functioning skills, but other studies fail to find 
any relationship. There are cohort, cultural, and dose-dependent effects that have not been separated out in these data. Different cohorts experience different media environments with infant-directed programs emerging around the turn of the 21st century. Using data collected in the 1970s, researchers found that television exposure during the elementary school years (ages 5-11) was related to attention problems in adolescence (Lanhuis et al., 2007). Similarly, a study that analyzed data collected in the 1980s found that heavy exposure to television programming at ages 1 and 3 predicted attention problems at age 7 (Christakis et al., 2004). A cross-sectional study of preschool children also found an association between television viewing at age 4 and concurrent behavioral problems (Miller et al., 2007).

In contrast, researchers who analyzed data collected in the 1990s found no relation between kindergarteners' television viewing and symptoms consistent with attention deficit hyperactivity disorder (ADHD) when the children entered first grade (Stevens \& Mulsow, 2006), nor was infants' television exposure associated with behavior problems during the preschool years in a sample of Danish children (Obel et al., 2004). Furthermore, a reanalysis of the dataset (National Longitudinal Survey of Youth) used by Christakis and colleagues (2004) indicates that only the top $10 \%$ of the sample was negatively affected by very high levels of television exposure at ages 1 and 3 , and this effect was eliminated when two additional covariates (poverty status and a measure of maternal skills) were added to the analysis (Foster \& Watkins, in press). Thus, television exposure per se does not appear to be the determining factor for attentional issues in the data from the National Longitudinal Survey of Youth.

The amount of exposure varies across studies and cultures. For instance, cross-cultural differences occur in the amount of children's television exposure, with U.S. samples reporting higher levels of exposure than European samples. In particular, more than $70 \%$ of U.S. 3-year-old children were exposed to television more than 2 hours per day (Christakis et al., 2004) whereas less than 6\% of Danish 3-year-olds had comparable levels of daily exposure (Obel et al., 2004).

School readiness. School readiness skills, such as vocabulary, preliteracy, numeracy, and spatial skills, are important acquisitions for early scholastic success (Neuman, Copple, \& Bredekamp, 2000; Scarborough \& Dobrich, 1994). Therefore, early experiences with linguistic, spatial, and numerical concepts are an important way to prepare children for school entry. The American Academy of Pediatrics' (1999) recommendation of no television exposure before age 2 and limited television exposure during the preschool years suggests that early screen exposure may disrupt school readiness skills. 
Merrill-Palmer Quarterly

Few studies have demonstrated a negative association between early television exposure and school readiness. Gentzkow and Shapiro (2008) compared children who grew up in cities such as Denver, where television access began in 1948, versus children who grew up in cities such as Seattle, where television access was introduced in 1954. Children did not differ on high school standardized test scores, suggesting that television exposure during preschool may not have deleterious effects on school-related outcomes. More recently, a negative association was found between levels of television exposure during infancy and language and visual motor skills at age 3 (Schmidt, Rich, Rifas-Shiman, Oken, \& Taveras, 2009). However, once maternal factors, particularly maternal education, were considered, the associations between early television exposure and language and visual motor development were no longer present (Schmidt et al., 2009). The kind of cognitive skills assessed also varies with television exposure. Zimmerman and Christakis (2005) found that more television exposure under age 3 was not associated with later mathematics performance, but was associated with worse reading comprehension and recognition scores at age 6 .

In summary, negative associations between television exposure and executive functioning have been found, but there has been relatively little support for an association between higher levels of television exposure and disrupted school performance. Moreover, variations in the specific kinds of program content to which children are exposed may partly explain any findings.

\section{Cognitive Skills and the Kind of Television Exposure}

Concerns regarding the relation between early television exposure and cognitive outcomes are shifting from a focus on quantity (amount) to the quality (type of content) of media being viewed. In particular, television exposure to child-directed programs, which are created specifically for infants and young children are differentiated from adult-directed programs, which are created for an adult audience (see Anderson \& Pempek, 2005). For example, looking time to child-directed programs is high, averaging approximately $70 \%$ for 12 - to 18 -month-olds (Barr, Zack, Garcia, \& Muentener, 2008). Children's programs often have very dense concentrations of perceptually salient features (Huston et al., 1981). These perceptually salient audio features can elicit attention at key points in television programs for preschool through elementary school, thereby improving comprehension of the contiguously presented content (Calvert, Huston, Watkins, \& Wright, 1982). 
Attention to adult-directed programs is far lower than it is for childdirected programs. One- to 3-year-old children attend to adult-directed television for only $5 \%$ of the time because they do not understand the content (Anderson \& Pempek, 2005). Despite the lower levels of attention, exposure to adult-directed content tends to be associated with more negative outcomes for children. Specifically, adult-directed television reduces the quantity of parent-child interactions, with parents responding passively rather than actively to their 1-to 3-year-olds' requests when an adult-directed television program was being played when compared to no television program being played (Kirkorian, Pempek, Murphy, Schmidt, $\&$ Anderson, 2009). Furthermore, during adult-directed television, infants' quality and quantity of play with toys was significantly worse when adult-directed television was on as compared to a period in which the television was off (Schmidt, Pempek, Kirkorian, Lund, \& Anderson, 2008). Presumably, adult-directed television disrupts play because perceptually salient audio characteristics elicit an attentional orienting reflex to the television screen, thus distracting infants from sustained play episodes. Because the content is incomprehensible to a young viewer, attention to the television screen is not sustained. Repeated disruptions to children's play may interfere with the development of attention. Early childhood exposure to higher levels of violent television programs, which contain high levels of perceptually salient formal features, are also associated with parental reports of attention problems in 7-year-olds (Zimmerman \& Christakis, 2007).

Exposure to well-designed television programs intended for children older than 2 years of age has clear positive effects on school readiness. In particular, childhood exposure to educational television programs such as Sesame Street, Mister Rogers' Neighborhood, Blue's Clues, and Dora the Explorer is associated with the development of preacademic skills, as well as long-term academic success (Anderson, Huston, Schmitt, Linebarger, \& Wright, 2001; Anderson et al., 2000; Rice, Huston, Truglio, \& Wright, 1990; Wright et al., 2001). Wright and his colleagues (2001), for example, found that 2-year-olds who were exposed more to child-directed educational programming, such as Sesame Street, had higher levels of school readiness than those who were primarily exposed to adult-directed television programs.

Effects of early media exposure vary, even for programs that are child directed. Early exposure to certain child-directed programs, such as Dora the Explorer, is associated with better subsequent language development, but viewing other child-directed programs, such as Teletubbies, is associated with poorer subsequent language outcomes (Linebarger \& Walker, 
Merrill-Palmer Quarterly

2005). Viewing DVDs designed for infants between the ages of 8 and 16 months was related to lower concurrent language scores (Zimmerman, Christakis, \& Meltzoff, 2007). However, exposure to educational television programs during early childhood was not associated with attention problems in 7-year-olds (Zimmerman \& Christakis, 2007).

Taken together, the results suggest that adult-directed television programs may disrupt early focused attention, toy play, and parent-child interactions, but that the effect of exposure to child-directed programs for very young children may vary depending on the specific kind of program. Certain programs designed for very young children may well be beneficial while others may be detrimental for cognitive outcomes.

Limitations of the studies assessing infant exposure to television may prevent a clear understanding of how early television exposure is associated with early and subsequent developmental outcomes. First, most of these studies relied on data that were collected when few products were being developed for an infant audience. The programs that infants were exposed to were created for much older audiences, such as adults, and were not developmentally appropriate for very young children. Second, most of these studies relied on longitudinal data that were not specifically collected to understand the relation between television exposure during infancy and later developmental outcomes. Third, not one longitudinal study assessed the association between exposure to adult-directed television programs versus exposure to child-directed television programs during infancy and associations with later developmental skills.

In the current study, we describe the relations between television exposure during infancy and preschool and cognitive skills at age 4 in a low-risk sample. We were specifically interested in the association between exposure to adult-directed television versus child-directed television programs on subsequent cognitive skill levels.

\section{Hypotheses}

Hypothesis 1. Based on data collected prior to the creation of infantdirected media, Christakis and colleagues (2004) indicated that high levels of television exposure at 1 and 3 years of age was linked to poorer attentional skills at age 7 . In the present study, we hypothesize that only early exposure to adult-directed television programs will disrupt later cognitive skills, including attention and executive functioning skills.

Hypothesis 2. Given that concurrent exposure to high levels of television during preschool was associated with poorer executive functioning (Miller et al., 2007) and that the kind of content is critical (Schmidt et al., 
2008), we predicted poorer cognitive outcomes would be associated with higher levels of exposure to adult-directed television at age 4 .

\section{Method}

\section{Participants}

Sixty healthy full-term children ( 28 boys and 32 girls) and their parents participated in the study when the children were infants between 12 and 18 months old $(M=15.77$ months, $S D=2.68)$ and again when the children were 4 years old $(M=49.42$ months, $S D=1.30)$ as part of a line of ongoing research studies. Participants were relatively homogeneous with regard to parental education, ethnicity, and socioeconomic status (SES). Almost all participants were middle-class children $(M$ SES $=80.96, S D=9.93$; Nakao $\&$ Treas, 1992) with highly educated parents; $98 \%$ of the parents held a college or postcollege degree. Participants were predominantly of Caucasian ethnicity $(81 \%), 12.1 \%$ were mixed race, $5.2 \%$ were Asian, and $1.7 \%$ were African American. Nearly $75 \%$ of these children were in child care prior to age 2 , and $85 \%$ were in child care at age 4 . Some children did not complete all outcome measures because of scheduling difficulties or child fatigue (see Table 3 for $n$ per measure).

\section{Materials and Procedure}

Families were visited in their homes when children were age 1 and age 4 . At each visit the procedures were described and parents completed an informed consent form.

Television diaries. To assess television usage in the home, parents completed a 24-hour diary of home television viewing at both time points, when their offspring were infants and then at age 4 . Infant diaries were completed between 2001 and 2004, and preschool diaries were completed between 2004 and 2007. All parents were given a television diary on the first day of the visit and asked to record the amount of time the television was on in the household, the name of the program being watched, and who was in the room when the television was on. Diaries were collected at the final visit (day 2 of infancy visit and day 4 of preschool visit). Parents were explicitly told to include times when the television was on, even if the child was not in the room or had gone to bed, and to indicate whether the day was a typical day for their child.

Cognitive skills measures. Trained research assistants assessed 4-yearolds on executive functioning, vocabulary, spatial skills, prenumeracy 
Merrill-Palmer Quarterly

skills, and preliteracy skills. Children were visited at a time of day designated by parents as one when their child was typically active and alert. Each measure took 10-15 minutes to administer.

The Behavior Rating Inventory of Executive Functioning-Preschool Version (BRIEF-P) (Gioia, Espy, \& Isquith, 2003) is a 63-item multiple-choice parent report measure assessing child behavior over the past 6 months. It yields five scales: (1) Inhibit: ability to resist impulses and stop behaviors; (2) Shift: ability to move from one situation to another; (3) Emotional Control: ability to modulate emotional responses; (4) Working Memory: ability to hold information in mind to complete a task; and (5) Planfulness and Organization: ability to plan effectively to achieve a goal. Higher scores on the BRIEF-P indicate poorer executive functioning. The internal consistency of the BRIEF-P ranges from .80 to .97 , and convergent validity with the Attention Deficit Hyperactivity Disorder Preschool Rating Scale ranges from .49 to .90 .

Shape School (Espy, 1997) is a measure of executive functioning designed for 3-to 6-year-old children. The assessment is presented as a storybook with four different scenes that describe colored circle and square figures as "students in a school setting." In the control condition, children are asked to identify the names of the students based on their color. In the switch condition, children are asked to name the students by shape if a student is wearing a hat but by color if the student is not wearing a hat. In the inhibit condition, children are asked to identify the names of students with happy faces and to skip the names of students with sad faces. The switch and inhibit condition includes students with and without hats, and students who are smiling or frowning. In this condition, both the Switch and Inhibit rules must be applied at once. Test-retest reliability for this measure ranges from .65 to .78 for completion time. The measure is also concurrently associated with other executive functioning tasks (Espy, Bull, Martin, \& Stroup, 2006).

For the Wechsler Preschool and Primary Scale of Intelligence-Revised (WPPSI-R) (Wechsler, 2002), children completed the vocabulary and block-design subtests. These two subtests are highly positively correlated with full-scale IQ scores over a wide range of measures (Sattler, 1982). During the vocabulary subtest, children were asked to define words they heard spoken aloud. The block-design subtest assessed spatial skills by asking children to recreate a particular shape after the experimenter demonstrates how to make it with blocks or shows a picture of the block design. Internal consistency ranges from .85 to .95 and concurrent validity with the WISC-III ranges from .46 to .63 on subtests and .79 to .89 on IQ estimates (Wechsler, 2002). 
The Peabody Picture Vocabulary Test (PPVT-III) (Dunn \& Dunn, 1997) is a nonverbal multiple-choice test that assesses receptive vocabulary. It is age normed on a nationally representative sample where a percentile rank score is obtained. It consists of 175 pages with four pictures on each page, with each page arranged in increasing order of difficulty. Children were given a word and asked to point to the corresponding picture. Internal consistency ranges from .92 to .95 and concurrent validity from .63 to .92 .

The Bracken Basic Concept Scale-Revised (Bracken, 1998) includes a basic School Readiness Composite (SRC) scale that assesses the child's knowledge of color, shape, letter identification, number/counting, and comparisons. Scores are age normed, and percentile rank is obtained. Internal consistency ranges from .47 to .98 and concurrent validity from .68 to .88 .

\section{Coding}

Television exposure. Parents completed 24-hour diaries tracking the names of programs and amount of television use in the household during infancy and at age 4. Television programs recorded in the television diaries were coded as either adult-directed or child-directed television. Programs coded as adult-directed television included news programs, game shows, situation comedies, and nature programs. Since many children's programs, like Power Rangers and That's so Raven, are created for an older child audience, these programs were also coded as adult-directed programming. Child-directed programming was defined as programs created for preschool audiences and younger and included PBS preschool programs (e.g., Arthur, Sesame Street, and Clifford), Nickelodeon preschool programs (e.g., Blues Clues and Dora the Explorer), baby-directed videos (e.g., Baby Mozart), and Disney movies (e.g., Finding Nemo). ${ }^{1}$

We calculated the amount of time that children were exposed to each type of content (adult-directed exposure, child-directed exposure, and overall total exposure) and the amount of time the television was on in the home (total household television). Overall total exposure was calculated by

${ }^{1}$ We also created an infant-directed television programming exposure category which included programs that were recommended for children under age 2, including baby videos and programs such as Arthur, Sesame Street, Clifford, Barney, Blues Clues, and Dora the Explorer that were positively associated with infant vocabulary development in studies by Linebarger and Walker (2005). The findings were identical to those for child-directed programming so for ease of readership we did not report these results separately. 
Merrill-Palmer Quarterly

summing the amount of time the child was present when there was an operating television set during both child-directed and adult-directed television programs. Total household television was calculated as a summation of all the time that the television set was turned on, independent of whether the child was present. Many children had no exposure to certain types of television programs (i.e., child-directed or adult-directed) so multiple regression analyses could not be run (see Table 1). For example, in infancy, 24\% of children had no exposure to child-directed television and $40 \%$ had no exposure to adult-directed programming, whereas, at age $4,85 \%$ of children had no reported exposure to adult-directed television programs (see Table 1).

To maintain appropriate power for our analyses, we divided each of the television content types into two groups by using a quartile cutoff system. Children who were in the top quartile of exposure for each type of content were coded as "high," whereas the rest of the children were coded as "low/ moderate." The cutoff points for each television content type are listed in Table 1. This criterion approach was based upon assessing dose-dependent effects (for similar approaches, see Christakis et al., 2004; Zimmerman et al., 2007). Higher doses of exposure to adult-direct television, for example, were expected to be more deleterious than low-to-moderate doses of exposure.

Cognitive measures. Standardized coding methods were used to calculate percentile rank, efficiency scores, and scaled scores for the cognitive measures. For BRIEF-P, a Global Executive Functioning Composite (GEC) score was calculated by summing the five original subscales (BRIEF-P) (Gioia et al., 2003). Three index scores were also calculated as follows: BRIEF-P Inhibitory Self-Control Index (Inhibit + Emotional Control), BRIEF-P Flexibility Index (Shift + Emotional Control), and BRIEF-P Emergent Metacognition Index (Working Memory + Planning/ Organization subscales).

To calculate scores on Shape School, a behavioral measure of executive functioning, we calculated efficiency scores from the Switch and Inhibit condition. Efficiency scores account for both speed and accuracy and were calculated as the number of correct responses divided by the total time to complete the Switch and Inhibit condition (Espy, 1997).

To estimate general intelligence, we averaged the scores on the WPPSI vocabulary and WPPSI block-design subscales and then multiplied that by 7 (the number of total subtests that make up the full-scale IQ score). This is the method recommended by the WPPSI to approximate full-scale IQ (Wechsler, 2002). For measures of vocabulary (PPVT) and school readiness (Bracken SRC), we added up the total number of correct answers and used the normed scales to determine percentile rank. 


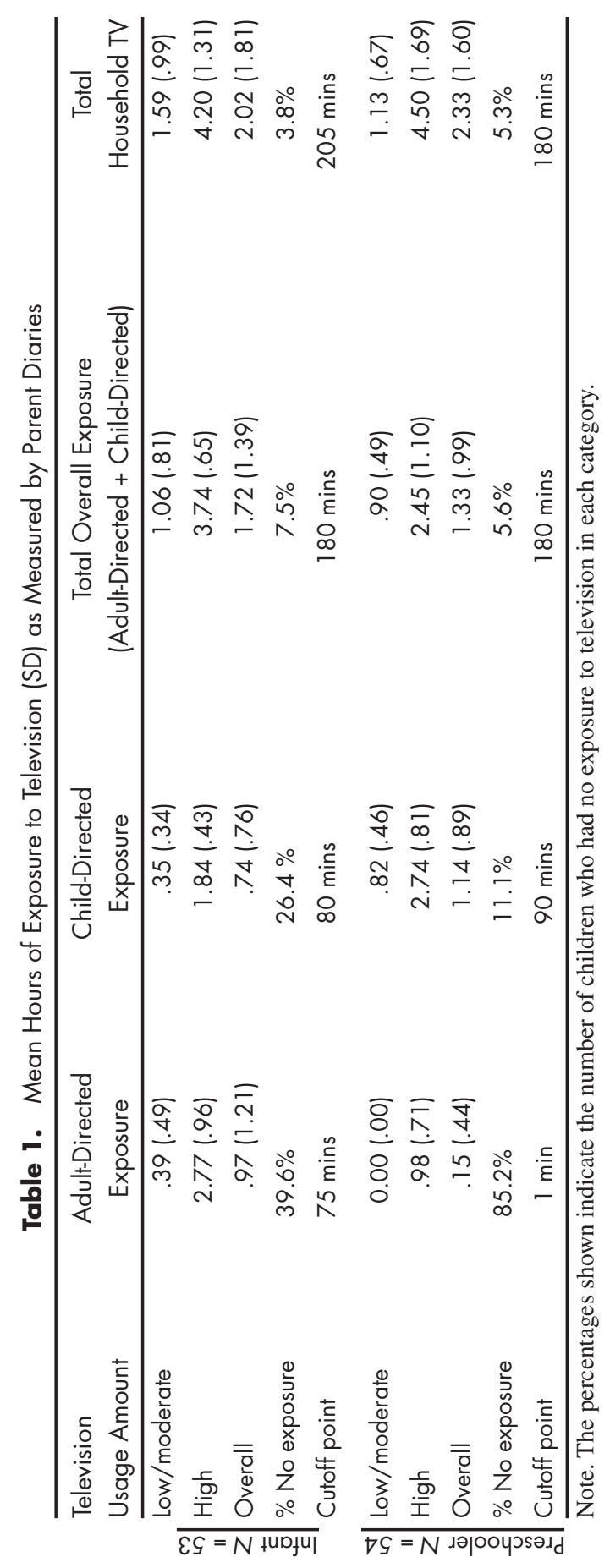




\section{Results}

\section{Analysis Plan}

We conducted descriptive analyses about television exposure and cognitive measures, followed by analyses that linked television exposure (during infancy and preschool) to each television content type (adult-directed exposure, child-directed exposure, overall total exposure, and total household television), with scores on the cognitive skills measures. Our analysis strategy involved $t$ tests, multivariate analyses of variance (MANOVAs), and multivariate analyses of covariance (MANCOVAs) controlling for demographic variables when they were significantly correlated with the dependent variables. All predictor variables were the dichotomous group variables for each type of television content (e.g., high adult-directed exposure vs. low/moderate adult-directed exposure). The cognitive measures were continuous scores. When cognitive measures were based on composite scores (e.g., BRIEF-P) or were highly correlated with one another (e.g., WPPSI, PPVT, Bracken SRC, and Shape School), they were included in the same analyses. For the analyses of BRIEF-P, first the GEC measure was analyzed using a $t$ test. If the BRIEF-P GEC measure was significant, further analyses were conducted to determine which subscales of the three BRIEF-P indices (Inhibitory Self-Control Index, Flexibility Index, and Emergent Metacognition Index) were associated with exposure to different types of television content.

\section{Descriptive Analyses}

Television exposure. As seen in Table 1, infants averaged 2 hours and preschoolers averaged 1 hour of television exposure per day. Although the absolute amount of exposure did not differ as a function of age, there were age differences between exposure to adult-directed and child-directed television. In particular, adult-directed television exposure was significantly higher for infants $(M=0.97 \mathrm{hrs}, S D=1.21)$ than for preschoolers $(M=0.15 \mathrm{hrs}$, $S D=0.44), t(49)=-4.19, p=.001$. Perhaps not surprisingly, given the number of shows that are directly marketed to preschoolers, exposure to childdirected television was significantly higher for preschoolers $(M=1.14 \mathrm{hrs}$, $S D=0.89)$ than for infants $(M=0.74 \mathrm{hrs}, S D=0.76), t(49)=2.42, p=.02$.

Cognitive measures. Means and standard deviation scores for the cognitive measures are presented in Tables 2 and 3. As seen in Table 2, the average BRIEF-P composite and individual test scores were all near 50, putting the sample at the 50th percentile. As seen in Table 3, average scores 


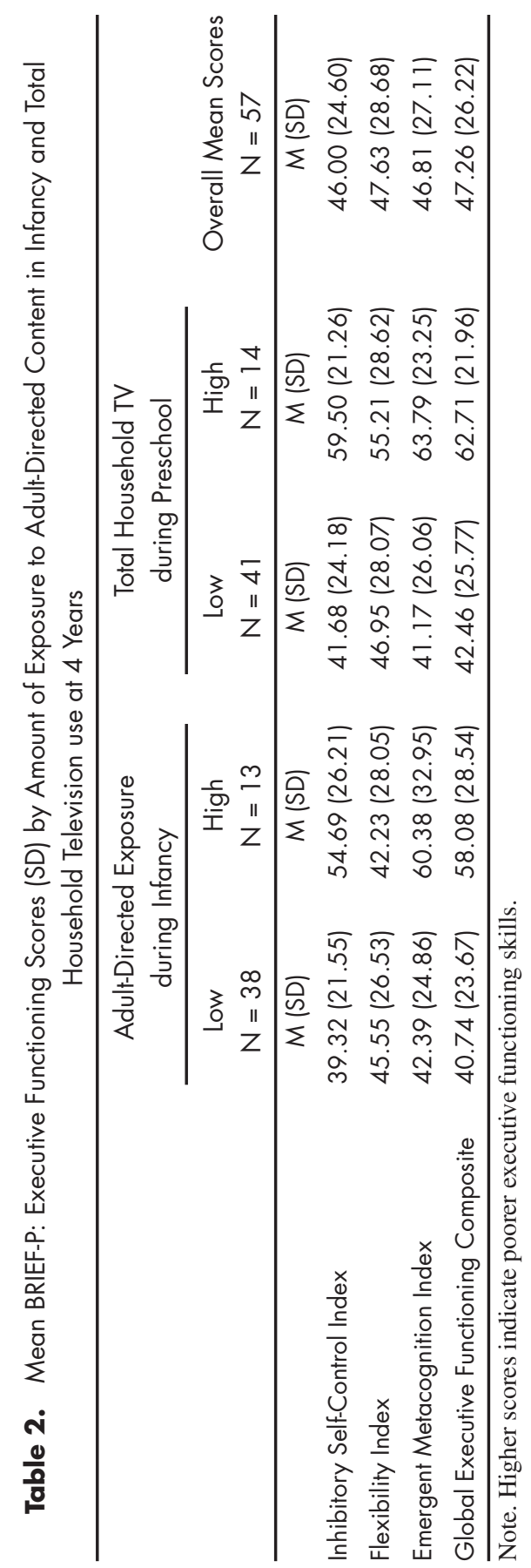


Table 3. Mean Scores on Cognitive Measures by Amount of Exposure to Adult-Directed Content at Age 4

\begin{tabular}{lccccc}
\hline & \multicolumn{2}{c}{$\begin{array}{c}\text { Adult-Directed } \\
\text { Exposure at Age } 4\end{array}$} & & \\
\cline { 2 - 3 } & Low & High & & Overall \\
& $N=37$ & $N=6$ & & Mean Scores \\
General Cognitive Assessments & $M(S E)$ & $M(S E)$ & $N$ & $M(S D)$ \\
\hline Wechsler Preschool and Primary Scale & 122.68 & 109.83 & 56 & 118.54 \\
of Intelligence Estimated Full-Scale IQ & $(18.23)$ & $(27.63)$ & & $(19.30)$ \\
Peabody Picture Vocabulary & 90.07 & 72.55 & 53 & 84.60 \\
Percentile rank & $(2.28)$ & $(5.69)$ & & $(19.52)$ \\
Bracken School Readiness Composite & 92.66 & 78.35 & 53 & 88.41 \\
Percentile rank & $(1.82)$ & $(4.54)$ & & $(15.97)$ \\
Shape School efficiency for Switch and Inhibit & .33 & .19 & 53 & .29 \\
& $(.02)$ & $(.06)$ & & $(0.15)$ \\
\hline
\end{tabular}

Note. Adjusted means are reported for the low/moderate and high exposure groups to control for parental education.

on estimated full-scale IQ (WPPSI) were $118.54(S D=19.30)$, which is at the 90th percentile. Language comprehension (PPVT) and school readiness (Bracken SRC) were at approximately the 85th percentile. Shape School has not been normed for national averages; in our sample, the mean score on the Switch and Inhibit condition subscale was $0.29(S D=0.15)$.

\section{Correlations among Cognitive Skills, Television Exposure, and} Demographic Measures

Consistent with many studies (e.g., Gue \& Harris, 2000; Sellers, Burns, $\&$ Guyrke, 2002), parental education was significantly correlated with the PPVT scores, and there was a trend linking parental education to the WPPSI, the Bracken SRC, and Shape School scores so it was included as a covariate in the remaining analyses with those cognitive measures (see Table 4). There were no significant correlations between SES, ethnicity, or gender, and any of the cognitive skills measures: WPPSI, PPVT, Bracken, Shape School, or the BRIEF-P subscales (see Table 4). Therefore, these three demographic variables were not included in further analyses. The lack of associations among these demographic variables may be because the participants were from a low-risk and relatively homogeneous population. 
As seen in Table 4, Pearson product-moment correlations revealed that the overall total exposure to television programs during infancy was not correlated with overall total exposure to television at 4 years of age. In addition, child-directed exposure and adult-directed television exposure were not associated with each other during infancy, nor at age 4 . This lack of correlation in viewing patterns may occur because infants do not choose their own television programs, whereas, at age 4 , children have more control over what they watch, can operate television sets and change channels, and may choose to view child-directed television programs (Rideout \& Hamel, 2006).

\section{Television Exposure and Cognitive Outcome Analyses}

BRIEF-P. An independent $t$ test was calculated to examine the difference between high versus low/moderate levels of adult-directed exposure during infancy on BRIEF-P GEC scores. There was a significant main effect of adult-directed exposure during infancy on GEC, $t(51)=-2.16$, $p=.04$, indicating that children who were exposed to high levels of adultdirected television during infancy were rated by their parents as worse $(M$ $=58.08, S D=28.54$ ) on Global Executive Functioning skills than those children who were exposed to low/moderate levels of adult-directed television programs $(M=40.74, S D=23.67)$. Next, a MANOVA was conducted to examine the association between high and low/moderate levels of adultdirected exposure during infancy and the three BRIEF-P composite indices. The overall model was significant, $F(1,51)=3.22, p=.03$, partial $\eta^{2}=$ .17 . There was a significant main effect of adult-directed exposure during infancy on both the Inhibitory Self-Control Index, $F(1,51)=4.41, p=.04$, partial $\eta^{2}=.08$, and Emergent Metacognition Index, $F(1,51)=4.28, p=$ .04 , partial $\eta^{2}=.08$. As seen in Table 2, the results indicated that children who had high levels of exposure to adult-directed television programs during infancy were rated worse on both index scores of the BRIEF-P than children who had low/moderate levels of exposure to adult-directed television programs during infancy. These findings support our first hypothesis that higher levels of exposure to adult-directed television during infancy would be associated with poorer executive functioning skills at age 4 .

An independent $t$ test was calculated between high and low/moderate levels of total household television at age 4 and the GEC of the BRIEF-P. The $t$ test was significant, $t(53)=-2.98, p<.01$, indicating that children living in homes with high levels of total household television were rated worse on the GEC measure than children living in homes with low/moderate levels of total household television (see Table 2). A MANOVA was conducted to examine the association between high and low/moderate levels 


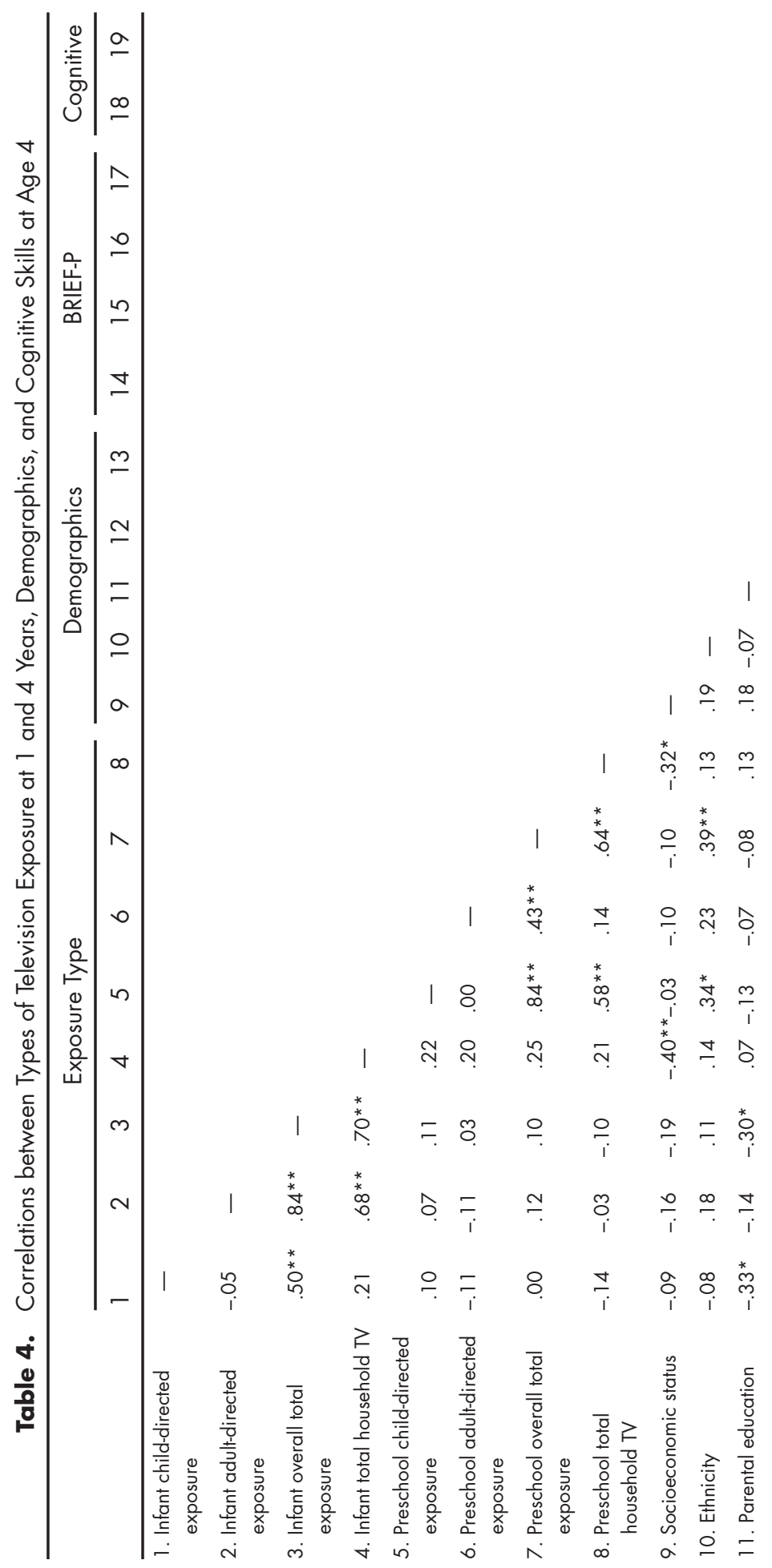




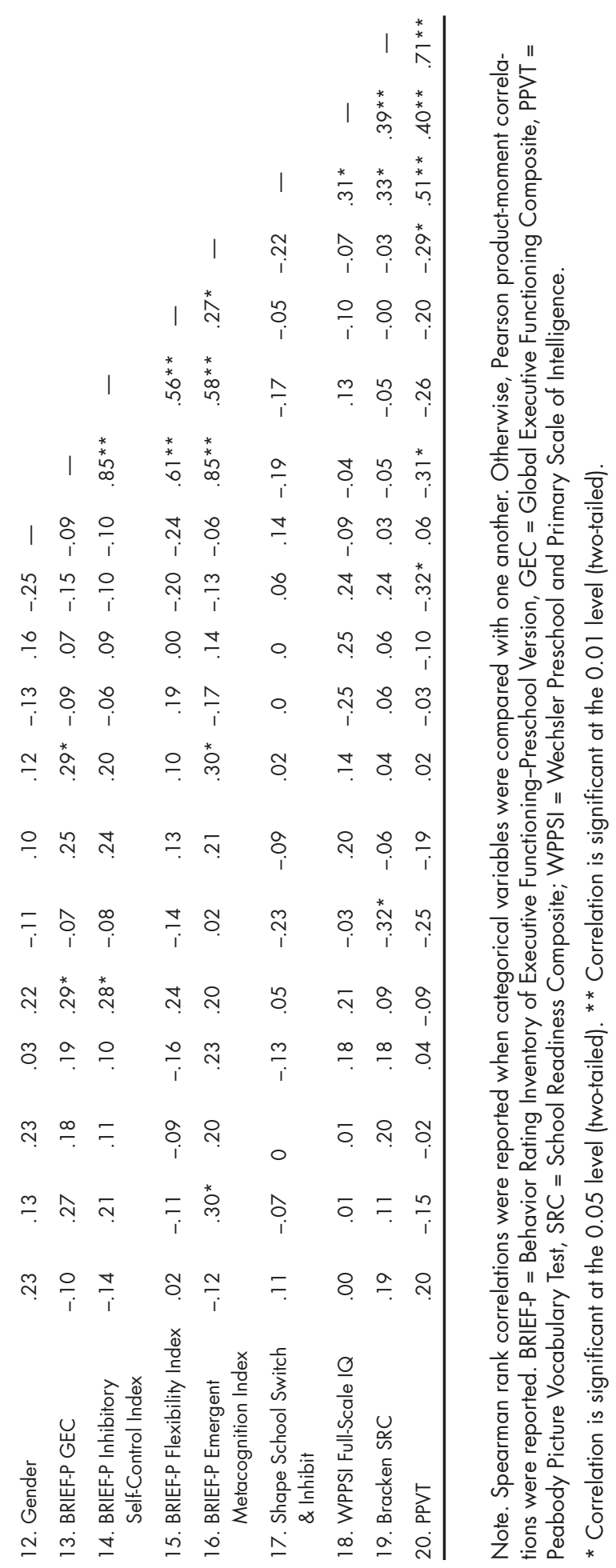


Merrill-Palmer Quarterly

of total household television and the three BRIEF-P indices. The overall model was significant, $F(1,53)=3.45, p=.02$, partial $\eta^{2}=.17$. There was a significant main effect of total household television during preschool on both the Inhibitory Self-Control Index, $F(1,53)=4.80, p=.03$, partial $\eta^{2}$ $=.08$ and the Emergent Metacognition Index, $F(1,53)=10.29, p<.01$, partial $\eta^{2}=.16$. These findings support our second hypothesis: Higher total household television at age 4 would be associated with poorer concurrent executive control skills (see Tables 2 and 4).

Six additional t-tests were conducted on the GEC of the BRIEF-P as a function of the remaining television content types during infancy (total household television, overall total exposure, and child-directed exposure) and at age 4 (overall total exposure, child-directed exposure, and adultdirected exposure). These analyses did not yield any significant effects with BRIEF-P GEC as the dependent variable.

Direct cognitive outcome measures. To assess the relation between television content type and cognitive outcomes, we conducted a MANCOVA between high and low/moderate levels of adult-directed exposure at age 4 and the cognitive measures (WPPSI, PPVT, Bracken SRC, and Shape School) with parental education as a covariate. The overall model was significant, $F(1,43)=4.00, p=.03$, partial $\eta^{2}=.26$. There was a significant main effect of adult-directed exposure at age 4 on the Receptive Vocabulary Subscale of the PPVT, $F(1,43)=8.14, p<.01$, partial $\eta^{2}=.17$, the Bracken SRC scale, $F(1,43)=8.53, p<.01$, partial $\eta^{2}=.18$, and the Shape School executive functioning measure, $F(1,43)=4.18, p=.05$, partial $\eta^{2}=.10$. In short, high levels of adult-directed television exposure at age 4 were associated with poorer cognitive and school readiness scores, as well as worse performance on the behavioral measure of executive functioning (see Table 3). These results are consistent with hypothesis 2: Higher levels of exposure to adult-directed television at age 4 would be associated with poorer cognitive outcomes.

A series of MANCOVAs were conducted to examine the relation between each television content type during infancy (adult-directed exposure, child-directed exposure, overall total exposure, and total household television) and preschool (child-directed exposure, overall total exposure, and total household television) and the four correlated cognitive measures with parental education as a covariate. There were no significant associations between any of the television content types and the scores on the cognitive measures.

\section{Discussion}

The purpose of this study was to describe the associations among the kinds of television content to which infants and preschool-aged children were 
exposed and their cognitive skills at age 4 . Our study is unique in that it finds a negative link with cognitive skills when infants and preschool-aged children are exposed to adult-directed television programs, but finds that exposure to child-directed content is not associated with cognitive skills at age 4 , at least in a low-risk sample. Put another way, when very young children were exposed to programs designed for their age group, there were no associations with executive functioning, cognitive, or school readiness scores at age 4 (see also Zimmerman \& Christakis, 2007).

By contrast, heavy exposure to adult-directed programming was linked to many of the cognitive problems previously reported in the literature (Christakis et al., 2004; Lanhuis et al., 2007; Zimmerman \& Christakis, 2005, 2007). In particular, 4-year-old children who had higher levels of exposure to adult-directed television programs during infancy were rated by their parents as worse on executive functioning skills, specifically Inhibitory Self-Control and Emergent Metacognition skills, than children who had low-to-moderate levels of exposure to adult-directed television during infancy. Moreover, higher levels of overall household television at age 4 were associated with poorer outcomes in executive functioning skills. Our findings are consistent with those of prior studies (Christakis et al., 2004; Lanhuis et al., 2007; Zimmerman \& Christakis, 2005, 2007), indicating that exposure to television content was negatively associated with better executive functioning and cognitive skills at older ages. Our data add to the body of literature by pinpointing the kind of program (i.e., adult-directed) that is associated with these deficiencies in cognitive skills.

Higher exposure to adult-directed programming at age 4 was also associated with poorer concurrent cognitive skills as measured by the Bracken SRC measure and the PPVT, as well as Shape School, a behavioral measure of executive functioning. These findings occur even when parental education was controlled. These findings are consistent with previous reports of associations between preschool deficits and preschool television exposure (see Miller et al., 2007), but again, we link these findings to exposure to adult-directed, not child-directed, programs.

There are at least three possible explanations for these findings. Early exposure to adult-directed television content might disrupt (1) attention regulation and/or (2) parent-child interaction or, alternatively, (3) children who are exposed to more television may have a predisposition to executive functioning and school readiness problems. These three explanations are not mutually exclusive.

Disruption of attention regulation. The association between high levels of adult-directed television exposure and poorer parent reports of their children's executive functioning at age 4 supports the argument that exposure 
to television programs could disrupt early attention processing and contribute to poorer cognitive outcomes (Christakis et al., 2004). The association between poorer efficiency scores on the behavioral measure of executive functioning at age 4 and higher levels of exposure to adult-directed television programs may also support this argument.

Disruption in attentional skills is more likely to occur following exposure to adult-directed programming than child-directed programming because television programs designed for adults are often incomprehensible to young audiences. When programming is incomprehensible, young children attend less to the program (Anderson, Lorch, Field, \& Sanders, 1980), and the content will not achieve sustained attention as when children view comprehensible children's programming (Schmitt, 2001). Even if children appear as though they are not attending to a program designed for adults, perceptually salient stimuli, such as a loud sound effect, may produce a reflexive orienting response to the television screen. According to Anderson and Pempek (2005), adult-directed television disrupts children's ongoing activity, including their play (Schmidt et al., 2008) and sustained attention, by repeatedly eliciting the orienting reflex to content that they do not comprehend. Over time, such repeated interruptions may disrupt inhibitory control. This disruption is more likely in homes with high levels of adult-directed television (Schmidt et al., 2008; but see Courage \& Setliff, 2009).

There is a caveat to this interpretation that remains unresolved. The beneficial uses of perceptually salient techniques by infants (Barr, Wyss, \& Somanader, 2009) and young children when viewing child-directed programs suggest that features become a learned signal that guides attention to programming that is age appropriate for the target audience (see Calvert et al., 1982). The implication is that perceptually salient auditory techniques affect children differently when placed in adult-directed versus child-directed programs. How do very young children learn to make this distinction? Perhaps they do not initially make this distinction at all, resulting in attention being pulled away from activities, such as play, to incomprehensible content when adult-directed programming is playing in the background. With age and experience, children learn that perceptually salient formal features, such as sound effects, can guide their attention to interesting, informative content, thereby moving them from a strictly reflexive to a purposeful attentional strategy when they hear a sound effect in a television program (see Calvert et al., 1982).

Exposure to adult-directed content may also disrupt some aspects of early school performance. More specifically, poorer performance on both the PPVT and the Bracken SRC scale were associated with higher levels 
of exposure to adult-directed television at age 4. These findings are consistent with those reported by Espy et al. (2004), who examined the concurrent relation between executive functioning, as measured by the BRIEF-P, and pre-math skills in 4-year-olds. Poorer Inhibit subscale scores, and to a lesser extent poorer Working Memory subscale scores, were associated with lower overall pre-math scores. Similarly, Bull and Scerif (2001) found that 7-year-old children with poor mathematics scores had poor inhibition and poor working memory scores. In our middle-class sample, children who were exposed to higher levels of adult-directed television programs still saw relatively low levels of television, averaging less than 1 hour of exposure per day. Even at this rate of adult-directed television exposure, there was an association with both poorer executive functioning skills and vocabulary scores at age 4 .

The correlational nature of the present study tempers our interpretation of the findings. Causal links and the direction of the relation between early media exposure and later cognitive skills cannot be established by our methodological approach. Exposure to adult-directed television might lead to attention regulation problems, but it is just as likely that children who are more vulnerable to attention regulation problems are exposed to more television programs (for a similar argument, see Christakis, 2009; Courage $\&$ Setliff, 2009; Obel et al., 2004).

Disruption of parent-child interactions. Another possible explanation for our findings is that parents are less involved with their children when adult-directed programming is turned on (Alston \& St. James-Roberts, 2004; Kirkorian et al., 2009). Higher parental involvement with a child is generally associated with better cognitive and executive functioning outcomes for children (e.g., Laible \& Song, 2006). It may be that when adultdirected television programs are on, parents are focused on the television content and not as engaged with, or interacting with, their child as much as when the television set is off (Kirkorian et al., 2009). Thus, if parents are less involved with their children when adult-directed programming is on the screen, children's cognitive and executive functioning skills are likely to be worse due to less face-to-face time with their parents (see also Christakis, 2009; Courage \& Setliff, 2009).

Perhaps parent-child interactions are not disrupted in the same way when children are watching child-directed content. When parents coview, which is approximately half of the time (Rideout \& Hamel, 2006), they are probably watching child-directed content to be with their child, not for their own entertainment. Indeed, research on parent-child interactions during child-directed television programs indicates that some parents interact with their children while viewing and encourage comprehension of 
the program by labeling content and asking questions (Barr et al., 2008). If parents actively interact with their children during child-directed programs but not during adult-directed programs, then one would expect negative associations only with exposure to adult-directed programming and executive functioning skills, as was found in this study. Future studies examining the context of television viewing and subsequent cognitive skills are needed (Christakis, 2009; Foster \& Watkins, in press).

Predisposition to poorer executive functioning. A third possible explanation for our findings is that parents who believe that their children are having more problems inhibiting behaviors may have children who do have more attention problems. Moreover, the parents themselves may have attention problems and perhaps be more interested in viewing television programs. Research shows that there is a strong genetic influence for attention deficit hyperactivity disorders (ADHDs) (e.g., Rietveld, Hudziak, Bartels, van Beijsteveldt, \& Boomsma, 2004). Barkley (2004) argued that the parents' ADHD symptoms strongly influence their children's media environment.

Children with ADHD watch significantly more television than do their non-ADHD peers (Acevedo-Polakovich, Lorch, \& Milich, 2007). Perhaps parents with attention problems themselves prefer to watch television, thereby exposing their children to more television programs. If parents regulate their own attention with higher levels of background stimulation, then television levels in these households will be higher and children will be exposed to more adult-directed television programs. Put another way, the television exposure levels may be a proxy for poorer executive functioning in general. Once again, future research is needed to assess the contributions of both genetic and environmental factors to assess whether some individuals are at higher risk for attentional problems (see Christakis, 2009; Courage \& Setliff, 2009)

\section{Neutral Findings with Child-Directed Media}

In contrast to the negative associations between exposure to adult-directed television programming and cognitive measures, we found that infant exposure to programs designed for infants and preschool-aged children was not associated with cognitive or school readiness scores at age 4 (see also Gentzkow \& Shapiro, 2008). These null results held even when a subset of programs that have been linked to improved language development in infants (Linebarger \& Walker, 2005) were analyzed separately. However, our sample size was relatively small, so there was limited power to test associations between infant exposure to specific infant-directed programs and cognitive outcomes. Additional empirical research is needed to assess 
whether positive educational claims made by producers of infant-directed videos translate to beneficial skills for infants.

\section{Cohort and Dose-Dependent Effects}

Taken together, our results provide a possible explanation for conflicting findings from longitudinal studies on the associations between exposure to television programming during infancy and their subsequent cognitive skills. More specifically, historical differences occurred in the kinds of programs that were available for different samples (i.e., cohorts) of children. Studies finding negative long-term links to very early television exposure (i.e., Christakis et al., 2004; Zimmerman \& Christakis, 2007) used data that were collected during the 1980s or mid-1990s, a time when no infant-directed programs and comparatively few child-directed programs were created for young audiences. In contrast, studies that find no effects of media exposure used data that were collected more recently, when educational preschool programs proliferated and infant-directed programs were beginning to emerge (e.g., Mistry et al., 2007; Obel et al., 2004; Schmidt et al., 2009; Stevens \& Mulsow, 2006; but see Miller et al., 2007). Even then, however, these studies did not separate out the links between exposure to television programs designed for children and infants from those designed for adults. The present study made such a distinction, demonstrating that exposure to higher levels of adult-directed programs during both infancy and preschool was associated with poorer performance on cognitive measures at age 4. In contrast, infant and preschool exposure to child-directed programs was not associated with any of our large battery of cognitive skills. In fact, our middle-class sample overall scored well above normed averages on our battery of cognitive measures.

\section{Limitations}

A major limitation of this exploratory study is that the participants were from a low-risk and relatively homogeneous population. These findings are therefore limited by the lack of generalizability at the population level and require replication with lower-income samples.

Although we controlled for demographic variables in our analysis, our low-risk sample could be buffered by favorable parent-child interactions that take place in middle-class homes (but see Gentzkow \& Shapiro, 2008). We are currently assessing parent-child interactions with their preschoolers as they view child-directed programs, but we do not have any data on parent-child interaction during adult-directed programming, an important area for future research. 
It is also possible that reducing exposure to adult-directed television programs could have a positive impact on the development of children's executive functioning skills, especially for subgroups that experience other risk factors, such as poverty (Christakis, 2009). We are currently examining this possibility by conducting an intervention study with low-income children, a group who is typically exposed to much higher levels of adultdirected television.

A second limitation is the use of television diaries to assess exposure. Although television diaries are a standard way to measure television exposure and are reliable (Anderson, Field, Collins, Lorch, \& Nathan, 1985), we might not have collected data on a typical day in the household.

A third limitation is that this study used correlational data. Although we found negative associations between higher exposure to adult-directed programming and poorer executive functioning and cognitive skills, we are unable to determine the direction of that relation. At issue is whether television exposure predicts poorer executive functioning skills or whether poorer executive functioning skills predict television viewing, or both (see also Courage \& Setliff, 2009).

\section{Conclusions}

The kind of television programs that children were exposed to during infancy and the preschool years was differentially associated with their cognitive skills at age 4. Exposure to child-directed programs during infancy or the preschool years had no relation to school readiness, vocabulary, or executive functioning. In contrast, higher exposure to adult-directed television programs during infancy and the preschool years was associated with poorer executive functioning skills, and exposure to adult-directed content at age 4 was associated with poorer school readiness and vocabulary skills. Even though the direction of the relation remains unclear, the emerging literature suggests that parents should limit their very young children's exposure to television programs designed for adults.

\section{References}

Acevedo-Polakovich, I. D., Lorch, E. P., \& Milich, R. (2007). Comparing television use and reading in children with ADHD and non-referred children across two age groups. Media Psychology, 9, 447-472.

Alston, E., \& St. James-Roberts, I. (2004). Home environments of 10-monthold infants selected by the WILSTAAR screen for pre-language difficulties. International Journal of Language and Communication Disorders, 40, 123-136. 
American Academy of Pediatrics, Committee on Public Education. (1999). Media education. Pediatrics, 104, 341-343.

Anderson, D. R., Bryant, J., Wilder, A., Santomero, A., Williams, M. E., \& Crawley, A. M. (2000). Researching Blue's Clues: Viewing behavior and impact. Media Psychology, 2, 179-194.

Anderson, D. R., Field, D. E., Collins, P. A., Lorch, E. P., \& Nathan, J. G. (1985). Estimates of young children's time with television: A methodological comparison of parent reports and time-lapse video home observation. Child Development, 56, 1345-1357.

Anderson, D. R., Huston, A. C., Schmitt, K. L., Linebarger, D. L., \& Wright, J. C. (2001). Early childhood television viewing and adolescent behavior: The recontact study. Monographs of the Society for Research in Child Development, 66(1), i-viii, 1-147.

Anderson, D. R., Lorch, E. P., Field, D. E., \& Sanders, J. (1980). The effects of TV program comprehensibility on preschool children's visual attention to television. Child Development, 52, 151-157.

Anderson, D. R., \& Pempek, T. (2005). Television and very young children. American Behavioral Scientist, 48, 505-522.

Barkley, R. A. (2004). ADHD and television exposure: Correlation as cause. ADHD Report, 12, 1-4.

Barr, R., Wyss, N., \& Somanader, M. (2009). Imitation from television during infancy: The role of sound effects. Journal of Experimental Child Psychology, $123,1-16$

Barr, R., Zack, E., Garcia, A., \& Muentener, P. (2008). Infants' attention and responsiveness to television increases with prior exposure and parental interaction. Infancy, 13, 30-56.

Bracken, B. A. (1998). Bracken Basic Concept Scale-Revised (BBCS-R). San Antonio, TX: Harcourt Assessments.

Bull, R., \& Scerif, G. (2001). Executive functioning as a predictor of children's mathematics ability: Inhibition, switching, and working memory. Developmental Neuropsychology, 19, 273-293.

Calvert, S. L., Huston, A. C., Watkins, B. A., \& Wright, J. C. (1982). The relation between selective attention to television forms and children's comprehension of content. Child Development, 53, 601-610.

Christakis, D. A. (2009). The effects of infant media usage: What do we know and what should we learn? Acta Paediatrica, 98, 8-16.

Christakis, D. A., Zimmerman, F. J., DiGiuseppe, D. L., \& McCarty, C. A. (2004). Early television exposure and subsequent attentional problems in children. Pediatrics, 113, 708-713.

Courage, M., \& Setliff, A. E. (2009). Debating the impact of television and video material on very young children: attention, learning, and the developing brain. Child Development Perspectives, 3, 72-78. 
Dunn, L. M., \& Dunn, L. M. (1997). Peabody Picture Vocabulary Test PPVT-III. Circle Pines, MN: American Guidance Service.

Espy, K. A. (1997). The Shape School: Assessing executive function in preschool children. Developmental Neuropsychology, 13, 495-499.

Espy, K. A., Bull, R., Martin, J., \& Stroup, W. (2006). Measuring the development of executive control with the Shape School. Psychological Assessment, 18, 373-381.

Espy, K. A., McDiarmid, M. M., Cwik, M. F., Stalets, M. M., Hamby, A., \& Senn, T. E. (2004). The contribution of executive functions to emergent mathematic skills in preschool children. Developmental Neuropsychology, 26, 465-486.

Foster, E. M., \& Watkins, S. (in press). The value of reanalysis: TV viewing and attention problems. Child Development.

Garrison, M., \& Christakis, D. A. (2005). A teacher in the living room: Educational media for babies, toddlers, and preschoolers. Menlo Park, CA: Henry J. Kaiser Family Foundation.

Gentzkow, M. A., \& Shapiro, J. M. (2008). Preschool television viewing and adolescent test scores: Historical evidence from the Coleman study. Quarterly Journal of Economics, 123, 279-323.

Gerstadt, C., Hong, Y., \& Diamond, A. (1994). The relation between cognition and action: Performance of children 31/2-7 years old on a Stroop-like day-night test. Cognition, 53, 129-153.

Gioia, G. A., Espy, K. A., \& Isquith, P. K. (2003). BRIEF-P: Behavior Rating Inventory of Executive Function-Preschool Version. Lutz, FL: Psychological Assessment Resources.

Gue, G., \& Harris, K. M. (2000). The mechanisms mediating the effects of poverty on children's intellectual development. Demography, 37, 431-447.

Hughes, C. (2002). Executive functions and development: Why the interest? Infant and Child Development, 11, 69-71.

Huston, A. C., Wright, J. C., Wartella, E., Rice, M. L., Watkins, B. A., Campbell, T., et al. (1981). Communicating more than content: Formal features of children's television programs. Journal of Communication, 31, 32-48.

Isquith, P. K., Gioia, G. A., \& Espy, K. A. (2004). Executive function in preschool children: Examination through everyday behavior. Developmental Neuropsychology, 26, 403-422.

Kirkorian, H. L., Pempek, T. A., Murphy, L. A., Schmidt, M. E., \& Anderson, D. R. (2009). The impact of background television on parent-child interaction. Child Development, 80, 1350-1359.

Laible, D., \& Song, J. (2006). Constructing emotional and relational understanding: The role of affect and mother-child discourse. Merrill-Palmer Quarterly, 52, 44-69. 
Lanhuis, C. E., Poulton, R., Welch, D., \& Hoancox, R. J. (2007). Does childhood television viewing lead to attention problems in adolescence? Results from a prospective longitudinal study. Pediatrics, 120, 532-537.

Linebarger, D. L., \& Walker, D. (2005). Infants' and toddlers' television viewing and language outcomes. American Behavioral Scientist, 48, 624-645.

Miller, C. J., Marks, D. J., Miller, S. R., Berwid, O. G., Kera, E. C., Santra, A., et al. (2007). Brief report: Television viewing and risk for attention problems in preschool children. Journal of Pediatric Psychology, 32, 448-452.

Mistry, K. B., Minkovitz, C. S., Strobino, D. M., \& Borzekowski, D. L. G. (2007). Children's television exposure and behavioral and social outcomes at 5.5 years: Does timing of exposure matter? Pediatrics, 120, 762-769.

Nakao, K., \& Treas, J. (1992). The 1989 socioeconomic index of occupations: Construction from the 1989 occupational prestige scores. Chicago: National Opinion Research Center.

Neuman, S. B., Copple, C., \& Bredekamp, S. (2000). Learning to read and write: Developmentally appropriate practices for young children. Washington, DC: National Association for the Education of Young Children.

Obel, C., Henriksen, T. B., Dalsgaard, S., Linnet, K. M., Skajaa, E., Thomsen, P. H., et al. (2004). Does children's watching of television cause attention problems? Retesting the hypothesis in a Danish cohort. Pediatrics, 114, 1372-1373.

Rice, M. L., Huston, A. C., Truglio, R., \& Wright, J. C. (1990). Words from Sesame Street: Learning vocabulary while viewing. Developmental Psychology, 26, 421-428.

Rideout, V., \& Hamel, E. (2006). The media family: Electronic media in the lives of infants, toddlers, preschoolers and their parents. Menlo Park, CA: Kaiser Family Foundation.

Rietveld, M. J. H., Hudziak, J. J., Bartels, M., van Beijsteveldt, C. E. M., \& Boomsma, D. I. (2004). Heritability of attention problems in children: Longitudinal results from a study of twins, age 3 to 12. Journal of Child Psychology and Psychiatry, 45, 577-588.

Sattler, J. M. (1982). Assessment of children's intelligence and special abilities. Boston: Allyn \& Bacon.

Scarborough, H. S., \& Dobrich, W. (1994). On the efficacy of reading to preschoolers. Developmental Review, 14, 245-302.

Schmidt, M. E., Pempek, T. A., Kirkorian, H. L., Lund, A. F., \& Anderson, D. R. (2008). The effects of background television on the toy play behavior of very young children. Child Development, 79, 1137-1151.

Schmidt, M. E., Rich, M., Rifas-Shiman, S. L., Oken, E., \& Taveras, E. M. (2009). Television viewing in infancy and child cognition at 3 years of age in a US cohort. Pediatrics, 123, 370-375. 
Schmitt, K. L. (2001). Infants, toddlers, and television: The ecology of the home. Zero to Three, 22, 17-23.

Sellers, A. H., Burns, W. J., \& Guyrke, J. (2002). Differences in young children's IQs on the Wechsler Preschool and Primary Scale of Intelligence-Revised as a function of stratification variables. Applied Neuropsychology, 9, 65-73.

Stevens, T., \& Mulsow, M. (2006). There is no meaningful relationship between television exposure and symptoms of Attention-Deficit/Hyperactivity Disorder. Pediatrics, 117, 665-672.

Wechsler, D. (2002). WPPSI-R: Wechsler Preschool and Primary Scale of Intelligence. San Antonio, TX: Psychological Corporation.

Wright, J. C., Huston, A. C., Murphy, K. C., St. Peters, M., Pinon, M., Scantlin, R., et al. (2001). The relations of early television viewing to school readiness and vocabulary of children from low-income families: The early window project. Child Development, 72, 1347-1366.

Zelazo, P. D., Carter, A., Reznick, J. S., \& Frye, D. (1997). Early development of executive function: A problem-solving framework. Review of General Psychology, 1, 198-226.

Zimmerman, F. J., \& Christakis, D. A. (2005). Children's television viewing and cognitive outcomes: A longitudinal analysis of national data. Archives of Pediatric and Adolescent Medicine, 159, 619-625.

Zimmerman, F. J., \& Christakis, D. A. (2007). Associations between content types of early media exposure and subsequent attention problems. Pediatrics, 120, 986-992.

Zimmerman, F. J., Christakis, D. A., \& Meltzoff, A. N. (2007). Associations between media viewing and language development in children under 2 years. Journal of Pediatrics, 151, 364-368. 
Copyright of Merrill-Palmer Quarterly is the property of Wayne State University Press and its content may not be copied or emailed to multiple sites or posted to a listserv without the copyright holder's express written permission. However, users may print, download, or email articles for individual use. 